\title{
Modelling and prevention of meshing interference in gear skiving of internal gears
}

\section{Conference Proceedings}

\author{
Andreas Hilligardt ${ }^{1}$ (D) - Jan Klose ${ }^{1} \cdot$ Michael Gerstenmeyer $^{1} \cdot$ Volker Schulze $^{1}$
}

Received: 9 April 2021 / Accepted: 11 July 2021 / Published online: 15 September 2021

(c) The Author(s) 2021

\begin{abstract}
Gear skiving is a highly productive process for machining of internal gears which are required in large quantity for electric mobility transmissions. Due to the complex kinematics of gear skiving, collisions of the tool and workpiece can occur during the process. Models exist to check for collisions of the tool shank or collisions in the tool run-out. While these models are sufficient for the process design of external gear skiving, at internal gears meshing interferences between tool and workpiece can appear outside the contact plane on the clearance face of the tool. To test for meshing interference requires comprehensive assessment of workpiece, tool and process kinematics. Currently, this is often done by time consuming CAD-simulation. In contrast, this paper presents an automated geometrical model for the analysis of meshing interference. The test for collisions is thereby performed along the whole height of the tool and especially includes constructive clearance angles and eccentric tool positions. The model is developed for user-friendly implementation and practical applications. The model for avoiding meshing interference in gear skiving is validated on two different process applications. In doing so, influences of the tool and process design on the interference situation are investigated, compared and discussed. Furthermore this new approach enables the prevention of meshing interference or tooth tip collisions in the early tool design by adjusting the process kinematics or the tool design itself. The maximal viable tool height can be quantified and recommendations for improving the clearance face situation are suggested.
\end{abstract}

Andreas Hilligardt

andreas.hilligardt@kit.edu

Jan Klose

jan.klose@kit.edu

Michael Gerstenmeyer michael.gerstenmeyer@kit.edu
Volker Schulze

volker.schulze@kit.edu

1 wbk Institute of Production Science, Karlsruhe Institute of Technology, Kaiserstr. 12, 76131 Karlsruhe, Germany 


\section{Modellierung und Vermeidung von Freiflächeninterferenz beim Wälzschälen von Innenverzahnungen}

\section{Zusammenfassung}

Das Wälzschälen von Zahnrädern ist ein hochproduktives Verfahren zur Bearbeitung von Innenverzahnungen, die in großen Stückzahlen für elektrische Antriebsstränge benötigt werden. Aufgrund der komplexen Kinematik des Verfahrens kann es während des Prozesses zu Kollisionen von Werkzeug und Werkstück kommen. Aktuell gibt es Modelle zur Überprüfung von Kollisionen des Werkzeugschaftes oder Kollisionen im Werkzeugauslauf. Für die Prozessauslegung des Außenwälzschälens sind diese Modelle ausreichend. Beim Wälzschälen von Innenverzahnungen kann es jedoch zusätzlich zu Kollisionen zwischen Werkzeug und Werkstück außerhalb der Spanebene auf der Freifläche des Werkzeugs kommen. Die Prognose dieser Kollisionsart erfordert eine gekoppelte Betrachtung von Werkstück, Werkzeug und Prozesskinematik. Gegenwärtig wird dies häufig durch zeitaufwändige CAD-Simulationen durchgeführt. Im Gegensatz dazu wird in dieser Arbeit ein punktbasiertes geometrisches Modell für die Analyse von Freiflächeninterferenzen vorgestellt. Die Prüfung erfolgt dabei über die gesamte Werkzeughöhe und schließt insbesondere konstruktive Freiwinkel und exzentrische Werkzeugpositionen ein. Das Modell zur Vermeidung von Freiflächeninterferenzen beim Wälzschälen wird in dieser Arbeit durch zwei unterschiedliche Prozesse validiert. Dabei werden Einflüsse der Werkzeug- und Prozessgestaltung auf die Interferenzsituation untersucht, verglichen und diskutiert. Der neue Ansatz ermöglicht die Vermeidung von Freiflächeninterferenzen oder Zahnkopfkollisionen in der frühen Werkzeugauslegung durch Anpassung der Prozesskinematik oder der Werkzeugauslegung. Die maximal zulässige Werkzeughöhe kann schnell quantifiziert werden und es werden Empfehlungen zur Verbesserung der Kollisionssituation vorgeschlagen.

\section{Introduction}

Gear skiving is a highly productive gear machining process for internal and external gears. Tool and workpiece are continuously meshing with multiple teeth in contact at any given time allowing high productivity and geometric accuracy. Thus gear skiving provides an attractive alternative to shaping. The potential for highly productive rough and finish gear machining of especially internal gears leads to a fast uptake of the technology. This development in the last decade is enabled by progress in dynamic machine tool precision as well as a demand driven by electric mobility drive trains [1]. But practical applications of gear skiving are sometimes obstructed by the challenging process conditions and small stable process windows which make the tool and process design an intricate task. The process angles change from small clearance to very negative rake angles during the process [2].

First and foremost, gear skiving of internal gears is limited by geometric restrictions of tool, workpiece and clamping. The workpiece and clamping need to allow for sufficient tool runout. Also the tool shaft may not interfere with the workpiece or clamping radially or axially [3]. But even if the minimal clearance angles during the process are sufficient, a clearance face collision between tool and workpiece may occur further away from the cutting edge and rake face [4]. This collision can lead to an effect similar to an unintended tip relief on the workpiece or serious tool failure [5]. This type of collision needs to be checked early on in tool design by geometric analysis. The problem is mentioned in the literature, but commonly only treated individually for each process by a CAD analysis [4].
The kinematics of the gear skiving process are based on crossed helical gears [8]. The flanks of the tool can resemble a spur or a helical gear but the tool profile deviates from an ideal involute geometry as the contact does not spread over the tool flank, because it is limited to the cutting edge. The tool and workpiece mesh under an axis crossing angle. This is creating the cutting speed in flank direction while the workpiece profile is created from a relative generation motion. The generation motion allows to affect the workpiece flank or profile line created from the same tool by adapting the process parameters like in hobbing or generating grinding [6]. In addition, gear skiving allows for asymmetric profile changes by the aforementioned eccentricity [4]. Thus modifications can be created or errors compensated on the machine which is important for setting up the process. But when changing process kinematics to influence workpiece geometry, potential collisions on the flank might be critical again. Thus the problem of flank collision is not only relevant in early tool design but also in later stages of process design and adaptation.

In theory, the collision on the clearance face appears similar to tooth tip interference of a pinion and an internal gear. In this case, the interference appears as a contact of the two gears outside the line of action. This effect is described for involute spur gear setups, where it is limiting the maximum tooth ratio between internal gear and pinion. The interference can be calculated by comparing the angular positions of tool and workpiece at the most critical point where the pinion outer and ring gear inner diameter intersect [7]. The tooth tip interference was also modelled for non-involute gear profiles in a setup with parallel axes. The gear profiles can be represented by spline functions [9]. 
Fig. 1 Process kinematics of internal gear skiving

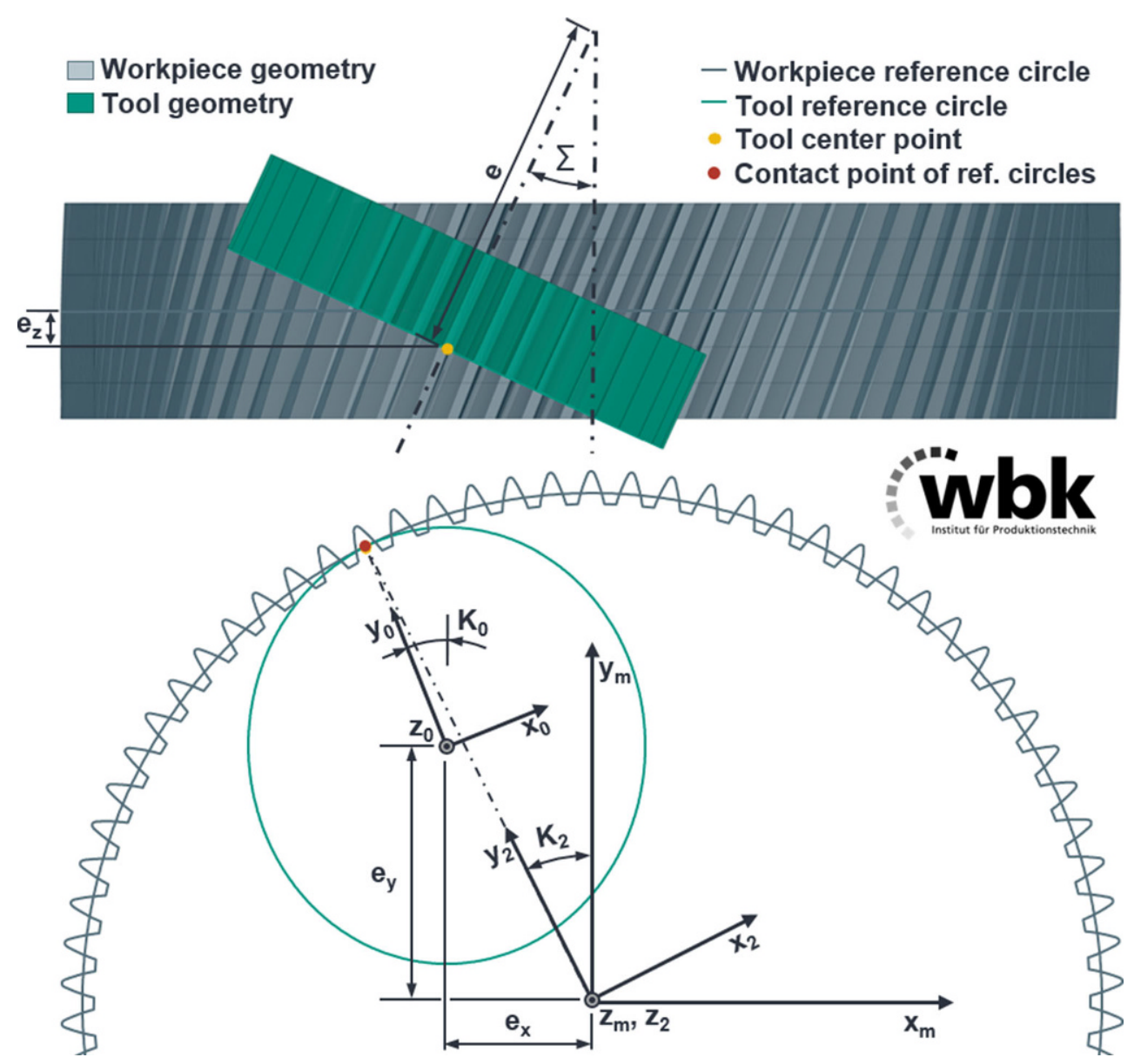

So far a three dimensional model for calculating tooth tip interference for crossed helical sets of a pinion and a ring gear is lacking which is less a problem for gearboxes as this configuration is rarely found. However, this model is necessary for collision detection in gear skiving. Furthermore, eccentric process kinematics and a conical tool geometry will have to be accounted for gear skiving as those are known to impact the interference situation.

\section{Process kinematics and coordinate systems}

In gear skiving, a distinction is made between off-center gear skiving with eccentric tool position and cylindrical tools and centered gear skiving with conical tools [8]. Centered gear skiving is a special form of eccentric gear skiving in which the eccentricity is zero. Similar to under-center turning, the off-center positioning creates a clearance angle that is necessary for chip formation with geometrically defined cutting edges. In case of centered processes, the tools are manufactured with a constructive clearance angle and thus a conical shape. The general process kinematics of gear skiving are shown in Fig. 1. To describe the process three coordinate systems are used: A fixed coordinate system (machine coordinate system) defined by $\mathrm{x}_{\mathrm{m}}, \mathrm{y}_{\mathrm{m}}$ and $\mathrm{z}_{\mathrm{m}}$; a tool coordinate system with $\mathrm{x}_{0}, \mathrm{y}_{0}$ and $\mathrm{z}_{0}$ and a workpiece coordinate system with $\mathrm{x}_{2}, \mathrm{y}_{2}$ and $\mathrm{z}_{2}$. The off-center tool positioning can be specified by either the tool eccentricity $e_{x}$, the rake face offset e or the position angle of the workpiece $\mathrm{K}_{2}$ or tool $\mathrm{K}_{0}$.

Tool eccentricity $\mathrm{e}_{\mathrm{x}}$ and rake face offset e can obviously be converted into each other using the axis crossing angle $\Sigma[8]$.

$e_{x}=e \cdot \sin \Sigma$

By representing the tilted tool reference diameter $\mathrm{d}_{\mathrm{ref}, 0}$ as an ellipse and pairing it in contact with the workpiece reference diameter $d_{r e f, 2}$, the tool eccentricity $e_{x}$ can be converted into position angles $\mathrm{K}_{0,2}$ and the second tool coordinate $\mathrm{e}_{\mathrm{y}}$ can be calculated.

$e_{x}=-\frac{d_{\text {ref, } 2}}{2} \cdot \sin K_{2}-\frac{z_{2}}{\left|z_{2}\right|} \cdot \frac{d_{\text {ref }, 0}}{2} \cdot \sin K_{0} \cdot \cos \Sigma$ 
$e_{y}=\frac{d_{\mathrm{ref}, 2}}{2} \cdot \cos K_{2}+\frac{z_{2}}{\left|z_{2}\right|} \cdot \frac{d_{\mathrm{ref}, 0}}{2} \cdot \cos K_{0}$

For off-center processes, machining takes place with an additional offset in the z-direction. This offset must be taken into account when projecting into a common transverse section and can be calculated using the axis crossing angle $\Sigma$ and tool position angle $\mathrm{K}_{0}$.

$e_{z}=-\frac{z_{2}}{\left|z_{2}\right|} \cdot \sin \Sigma \cdot \sin K_{0} \cdot \frac{d_{\mathrm{ref}, 0}}{2}$

Depending on the method of tool design, the reference circles correspond to the operating pitch circles or, in some cases, to the tool tip circle and workpiece root circle. The tool position for external and internal gears is calculated using the signed number of workpiece teeth $z_{2}$ which are negative for internal gears.

Furthermore, the combination of axis crossing angle and position angles $\mathrm{K}_{0}$ allows to evaluate the effective head clearance angle $\alpha_{e}$

$\tan \alpha_{e}=\tan \Sigma \cdot \sin K_{0}$

With the workpiece position angle $\mathrm{K}_{2}$ the effective axis crossing angle $\Sigma_{\mathrm{e}}$ is obtained [10].

$\tan \Sigma_{e}=\tan \Sigma \cdot \cos K_{2}$

To ensure symmetrical alignment of the tool in the workpiece tooth gap, the helix angles of workpiece and tool at their corresponding reference diameters $\beta_{\text {ref, } 2}$ and $\beta_{\text {ref }, 0}$ should add up to the effective axis crossing angle $\Sigma_{\mathrm{e}}$.

$\Sigma_{e}=-\frac{z_{2}}{\left|z_{2}\right|} \beta_{\text {ref }, 0}-\beta_{\text {ref }, 2}$
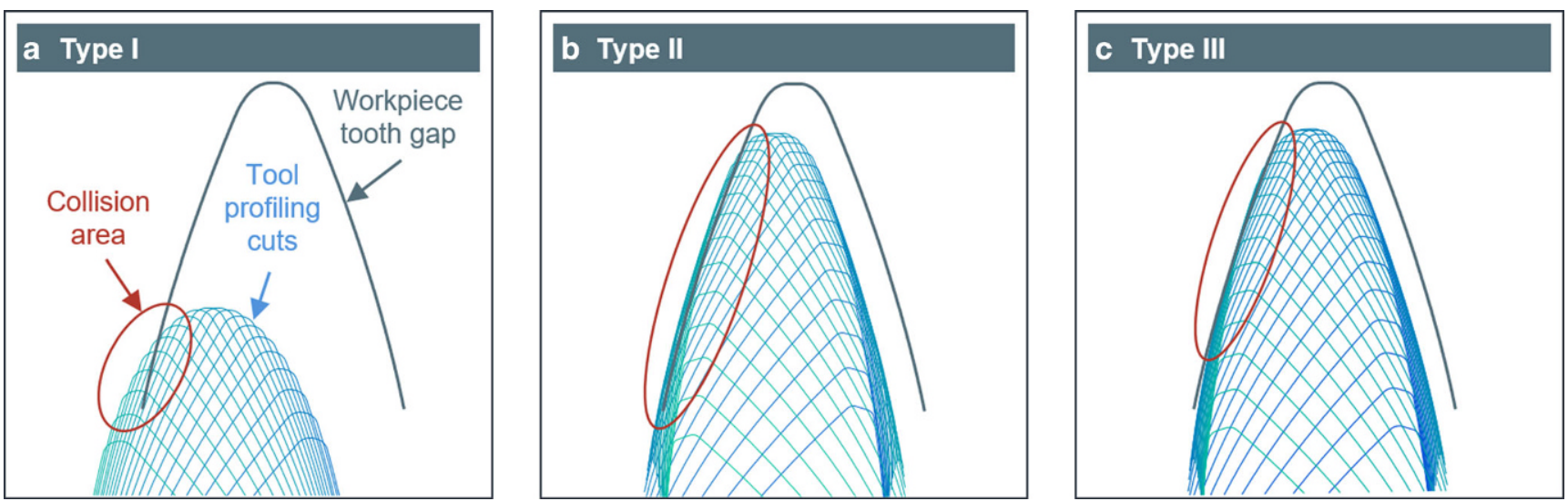

Fig. 2 Classification of interference types illustrated on the basis of profiling cuts at a tool height above the rake plane 

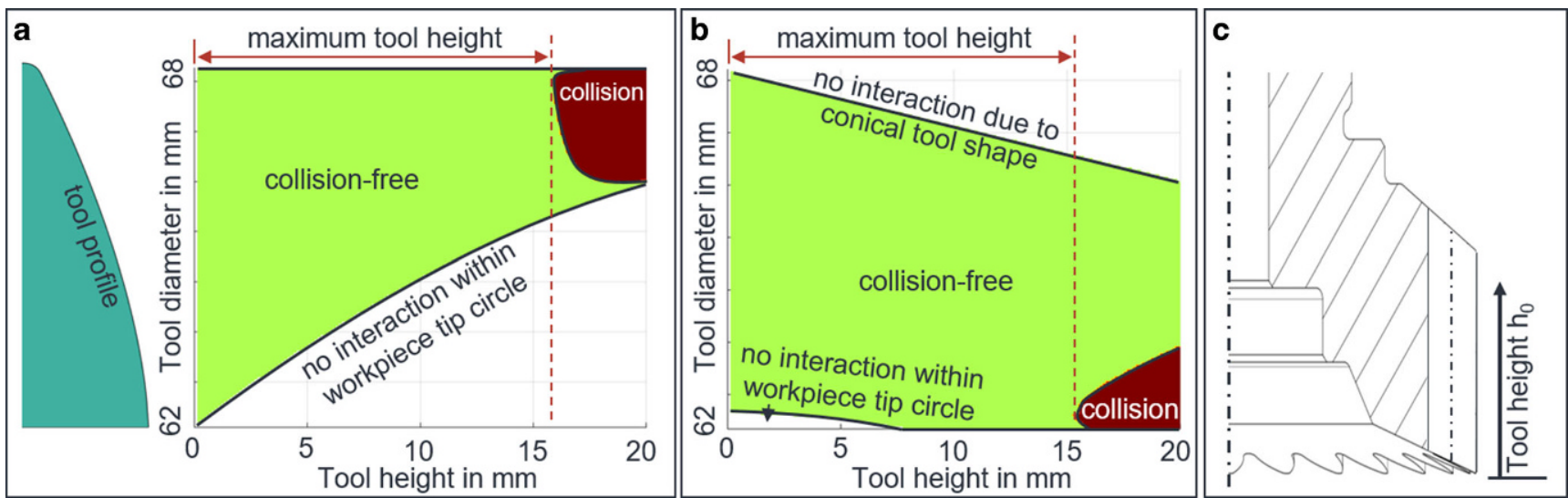

Fig. 3 a Example interference type I (off-centered process) b Interference type II (centered process) c Definition of the tool height

only happens in processes with very small clearance angles and unfavorable helix angles. Processes like this would also not show any working chip formation. Therefore, only the first two cases are of importance for industrial gear skiving and need verification. The two relevant interference types always include the edge of the workpiece tip so only this point can be considered on the workpiece side. On the tool side, the head contour is decisive in the first case, while the flank is decisive in the second case. But as the location of a collision is unknown beforehand, it must be tested along the entire tool profile as well as the tool height. Examples for corresponding investigations are shown as characteristic diagrams in Fig. 3. Here, the diameter of all profile points of one tool flank is plotted on the ordinate and the tool height on the abscissa.

Collision-free areas are highlighted in green, while collision-critical areas are marked in red. Fig. 3a shows an off-center process with cylindrical tool. The collision starts at the tool tip and reaches onto the flank further along the tool height. Interference type II is shown in Fig. $3 \mathrm{~b}$ for a centered process with a conical tool. Collision starts at the bottom of the tool flank. In both cases the maximum viable tool height is limited by the first interference of the respective type.

\section{Interference modeling}

The presented modeling method for relevant interference of types I and II is based on the distance between discrete tool points and the point at the workpiece tooth tip. To minimize the computational effort, calculation is performed in homogeneous coordinates [8]. Thus translations and rotations can be described as a linear mapping. The calculation has to be carried out for a discrete number of points along the tool profile as well as along the tool height in order to detect both interference types. For only interference type I, the tools tip end point is sufficient. Furthermore, generally both flanks must be calculated, as the rotational offset between tools envelope and workpiece tooth space can change direction.

The first step is modeling the tool profile along the tool height $\mathrm{h}_{0}$, see Fig. 3c. While unvaried for cylindrical tools, a conical relief angle may be achieved in different ways to create the same workpiece profile after tool reconditioning. A common approach is to modify the tools profile shift factor $\mathrm{x}_{0}$ according to the constructive clearance angle $\alpha_{\mathrm{c}}[6]$. Unlike a beveloid gear, only the profile shift changes along height, so a symmetrical tool profile is maintained over the entire height, as it is necessary in a centered process. With the normal module $m_{n}$ of the tool, the change of profile shift $\Delta \mathrm{x}$ can be determined. Consequently the tooth thickness is described by a change of the half angle $\Delta \psi$ with the normal pressure angle of the tool $\alpha_{\mathrm{n}}$.

$\Delta x=\frac{\sin \alpha_{c} \cdot h_{0}}{m_{n}}$

$\Delta \psi=\frac{2 \cdot \Delta x \cdot \tan \alpha_{n}}{\left|z_{0}\right|}$

For a tool with a helix angle $\beta_{0}$, rotation trough the helix must also be taken into account. The rotation $\varphi_{\beta 0}$ results from the tool pitch circle $\mathrm{d}_{0}$ and the observed tools height $\mathrm{h}_{0}$.

$\varphi_{\beta 0}=\frac{2 \cdot h_{0} \cdot \tan \beta_{0}}{d_{0}}$

With Eqs. 8-10, the description of a tool profile point along the tool height $\overline{\mathrm{p}_{0}}$ is obtained from the coordinates $p_{x, 0}, p_{y, 0}$ and $p_{z, 0}$ in the rake face. The signed tooth thickness half angle $\Delta \psi$ changes depending on whether the profile point is on the left or right flank of the tool.

The minimum distance between tool profile point and workpiece head point is evaluated in the machine coordinate system and projected into a common transverse section. This first requires a transformation taking into account the process kinematics, see Fig. 1. The rotation around the tool 
$\bar{p}_{0}^{(0)}=\left(\begin{array}{cccc}\cos \varphi_{\beta 0} & -\sin \varphi_{\beta 0} & 0 & 0 \\ \sin \varphi_{\beta 0} & \cos \varphi_{\beta 0} & 0 & 0 \\ 0 & 0 & 1 & 0 \\ 0 & 0 & 0 & 1\end{array}\right)\left(\begin{array}{cccc}\cos \pm \Delta \psi & -\sin \pm \Delta \psi & 0 & 0 \\ \sin \pm \Delta \psi & \cos \pm \Delta \psi & 0 & 0 \\ 0 & 0 & 1 & h_{0} \\ 0 & 0 & 0 & 1\end{array}\right)\left(\begin{array}{c}p_{x, 0} \\ p_{y, 0} \\ p_{z, 0} \\ 1\end{array}\right)$

Fig. 4 Tool profile point description along tool height

${\overline{p_{0}}}^{(m)}=\left(\begin{array}{cccc}\cos \sum \cdot \cos \varphi_{0} & -\cos \sum \cdot \sin \varphi_{0} & \sin \sum & e_{x} \\ \sin \varphi_{0} & \cos \varphi_{0} & 0 & e_{y} \\ -\sin \sum \cdot \cos \varphi_{0} & \sin \sum \cdot \sin \varphi_{0} & \cos \sum & -e_{z} \\ 0 & 0 & 0 & 1\end{array}\right){\overline{p_{0}}}^{(0)}$

Fig. 5 Tool profile point in the machine coordinate system

$\bar{p}^{(m, t)}=\left(\begin{array}{cccc}\cos \varphi_{\beta 2} & -\sin \varphi_{\beta 2} & 0 & 0 \\ \sin \varphi_{\beta 2} & \cos \varphi_{\beta 2} & 0 & 0 \\ 0 & 0 & 1 & -p_{z, 0}^{(m)} \\ 0 & 0 & 0 & 1\end{array}\right){\overline{p_{0}}}^{(m)}$

Fig. 6 Tool point projection into the xy-plane

axis as a result of the tool rotation is described by the angle $\varphi_{0}$.

The tool point is projected into the xy-plane of the machine coordinate system along the workpiece helix depending on its $\mathrm{z}$-coordinate $\mathrm{p}_{\mathrm{z}, 0}{ }^{(\mathrm{m})}$.

$\varphi_{\beta 2}=\frac{2 \cdot p_{z, 0}^{(m)} \cdot \tan -\beta_{2}}{d_{2}}$

In the next step, the positions where the tool profile point enters and leaves the workpiece tip form circle $\mathrm{d}_{\mathrm{Fa}, 2}$ must be calculated. This is done by solving equation 15 .

$d_{F a, 2}=2 \cdot\left|{\overline{p_{0}}}^{(m, t)}\left(\varphi_{0}\right)\right|$

Of the two solutions, the ingoing angle is used for tool points on the leading flank and the corresponding outgoing angle for points on the trailing flank. The tool rotation angle $\varphi_{0}$ and workpiece rotation angle $\varphi_{2}$ are coupled by the teeth ratio and the position angles $\mathrm{K}_{0,2}$.

$\varphi_{2}=K_{2}+\left(\varphi_{0}-K_{0}\right) \frac{z_{0}}{z_{2}}$

Fig. 7 Example of Interference situation at tool height $\mathrm{h}_{0}$
Thus, the position of the tip form circle point $\overline{\mathrm{p}_{2}}$ of the considered workpiece flank is calculated.

${\overline{p_{2}}}^{(m, t)}=\left(\begin{array}{cccc}\cos \varphi_{2} & -\sin \varphi_{2} & 0 & 0 \\ \sin \varphi_{2} & \cos \varphi_{2} & 0 & 0 \\ 0 & 0 & 1 & 0 \\ 0 & 0 & 0 & 1\end{array}\right) \bar{p}_{2}^{(2)}$

In the final step, the distance $\overline{\Delta p}$ between the workpiece tip form point and the considered tool profile point in the common transverse section can be evaluated, see Fig. 7.

$\overline{\Delta p}={\overline{p_{0}}}^{(m, t)}-{\overline{p_{2}}}^{(m, t)}$

Interference is present if the $\mathrm{x}$-component of the distance takes on negative values for the right workpiece flank and positive values in case of the left workpiece flank.

\section{Validation and examples}

As part of the investigation of gear skiving of highly tempered materials, an off-centered gear skiving process with a cylindrical tool was designed at the wbk Institute of Production Technology with the data listed in Table 1; [5]. At first, no calculation for interference was carried out in process design. Subsequently, type I interference occurred during the experimental procedure resulting in unintended tip edge fracture of the workpiece, as shown in Fig. 8b. Furthermore, the tool failed due to massive outbreaks, which protruded deep into the clearance face, see Fig. 8c. Verification of the interference situation by the presented model showed that interference occurred at a tool height of only $11.9 \mathrm{~mm}$ in the finishing tool pass. As a result, the process design was adapted to an axis crossing angle of $25.733^{\circ}$ and an increased eccentricity with a tool position angle $\mathrm{K}_{0}$ of $32.59^{\circ}$. For this purpose, an iterative optimization of the two parameters was performed to identify a collision-free condition. However, the kinematic change produced profile angle deviations $\mathrm{f}_{\mathrm{H} \alpha}$ of -6 and $15 \mu \mathrm{m}$ on the workpiece. In a following set of experiments, the tool height was reduced to only $10 \mathrm{~mm}$ by eroding, regrinding and recoating the tool.

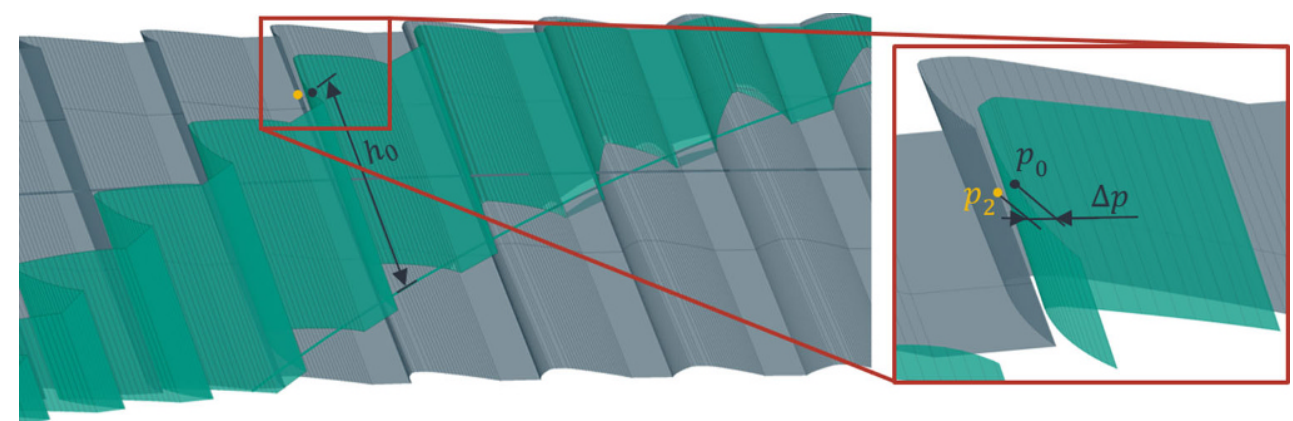


Table 1 Workpiece, tool and process data of example 1

\begin{tabular}{llllll}
\hline Workpiece data & & & & \\
Number of teeth & $\mathrm{z}_{2}$ & -82 & Normal pressure angle & $\alpha_{\mathrm{n}}$ & $17.5^{\circ}$ \\
Helix angle & $\beta_{2}$ & $22.5424^{\circ}$ & Normal module & $\mathrm{m}_{\mathrm{n}}$ & $1.34 \mathrm{~mm}$ \\
Tip diameter & $\mathrm{d}_{\mathrm{a} 2}$ & $115.8 \mathrm{~mm}$ & Generating addendum modification coefficient & $\mathrm{x}_{\mathrm{e}}$ & 0.16546 \\
Root diameter & $\mathrm{d}_{\mathrm{f} 2}$ & $123 \mathrm{~mm}$ & Tooth width & $\mathrm{b}_{2}$ & $30 \mathrm{~mm}$ \\
Tool and process data & & & & $0_{\mathrm{c}}$ \\
Number of teeth & $\mathrm{z}_{0}$ & 48 & Constructive head clearance angle & $0^{\circ}$ \\
Helix angle & $\beta_{0}$ & $0^{\circ}$ & Stair angle & $0^{\circ}$ \\
Tip diameter & $\mathrm{d}_{\mathrm{a} 0}$ & $69.03 \mathrm{~mm}$ & Position angle & $\mathrm{K}_{2}$ & $26^{\circ}$ \\
Root diameter & $\mathrm{d}_{\mathrm{f} 0}$ & $61.4 \mathrm{~mm}$ & Axis crossing angle & $\Sigma$ & $24.75^{\circ}$ \\
\hline
\end{tabular}

With the refurbished tool below the maximum tool height calculated in Fig. 8a, the test was successfully carried out with the original kinematics and without the additional profile errors on the workpiece.

For this process, the influences of number of tool teeth and tool eccentricity on the maximum usable tool height were investigated as key variables in tool design, see Fig. 9. While reducing the number of tool teeth leads to an almost linear increase of viable tool height, increasing the effective clearance angle by tool eccentricity shows an initial decrease of the maximum tool height. Here, the type of interference changes from type II to type I. Finally, the usable tool height increases after a plateau area and reaches an area without any interaction before the tool tip reaches the workpiece tip circle and the process is collision-free for all heights.

Due to the low profile angle and the tooth height, this type of gear, as used in modern electric mobility transmissions, is particularly susceptible to the interference problem. Therefore a central process with the parameters listed in Table 2 was chosen as second example. In the designed setup it can be executed with a maximum tool height of $24 \mathrm{~mm}$. But gear skiving offers the advantage that profile angle deviations in the manufactured workpiece, which are caused among other things by operating displacements, can be corrected by adjusting the kinematics. For example, the profile angle deviation of one flank can be corrected while the other flank remains unchanged by combining adjustment of the axis crossing angle and the eccentricity of the tool position. For this process, the presented method was used to investigate the maximum tool height depending on the applied profile angle correction. The profile angle deviation is evaluated between the forming circles with diameters of 135.3 and $130 \mathrm{~mm}$. In Fig. 10a, the maximum tool height up to the occurrence of interference is plotted over the correction of the profile angle deviation on the left flank. The corresponding adjustments of the kinematics are shown in Fig. 10b. It becomes clear how small the viable range for corrections can be when machining internal gears. With a tool height of $20 \mathrm{~mm}$, only a profile angle deviation of $2 \mu \mathrm{m}$ can be compensated. If the tool height is reduced to $15 \mathrm{~mm}$ corrections of up to $4.25 \mu \mathrm{m}$ are possible. (Fig. 10).

\section{Discussion}

The presented numerical modelling of the three-dimensional problem can be used to easily assess the interfer-
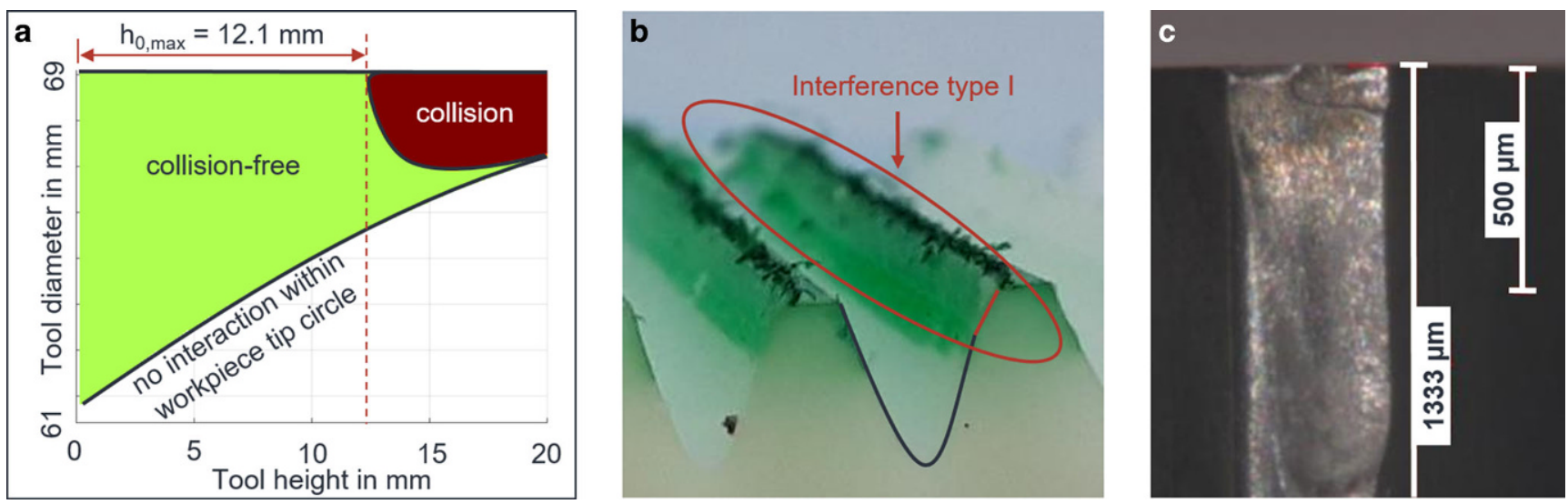

Fig. 8 a Characteristic map of collision b Clearance face collision at a plastic ring gear $\mathbf{c}$ Clearance face damage of a tungsten carbide tool caused by collision 
Table 2 Workpiece, tool and process data of example 2

\begin{tabular}{|c|c|c|c|c|c|}
\hline \multicolumn{6}{|l|}{ Workpiece data } \\
\hline Number of teeth & $\mathrm{z}_{2}$ & -107 & Normal pressure angle & $\alpha_{\mathrm{n}}$ & $17.5^{\circ}$ \\
\hline Helix angle & $\beta_{2}$ & $-18.04^{\circ}$ & Normal module & $\mathrm{m}_{\mathrm{n}}$ & $1.15 \mathrm{~mm}$ \\
\hline Tip diameter & $d_{a 2}$ & $130 \mathrm{~mm}$ & Generating addendum modification coefficient & $\mathrm{x}_{\mathrm{e}}$ & -1.178 \\
\hline Root diameter & $\mathrm{d}_{\mathrm{f} 2}$ & $135.6 \mathrm{~mm}$ & Tooth width & $\mathrm{b}_{2}$ & $35 \mathrm{~mm}$ \\
\hline \multicolumn{6}{|c|}{ Tool and process data } \\
\hline Number of teeth & $\mathrm{z}_{0}$ & 74 & Constructive head clearance angle & $\alpha_{c}$ & $6.48^{\circ}$ \\
\hline Helix angle & $\beta_{0}$ & $3.1^{\circ}$ & Stair angle & $\tau$ & $0^{\circ}$ \\
\hline Tip diameter & $\mathrm{d}_{\mathrm{a} 0}$ & $89.1 \mathrm{~mm}$ & Position angle & $\mathrm{K}_{2}$ & $0^{\circ}$ \\
\hline Root diameter & $\mathrm{d}_{\mathrm{f} 0}$ & $81.5 \mathrm{~mm}$ & Axis crossing angle & $\Sigma$ & $22^{\circ}$ \\
\hline
\end{tabular}

ence. It works for conical tools and cylindrical tools with eccentric processes and is thus applicable to all gear skiving processes. The discretization of the numerical model poses a challenge to calculation accuracy. Critical processes need to be tested at multiple points along the tool height. The choice and distance of the points tested may limit the validity of the results.

The collision between workpiece and tools clearance face was divided into three types, where only type I are II are practically relevant for gear skiving. For interference type I the model requires the process kinematics, workpiece tip form point and tool tip edge point as input. This data can usually be extracted from the tools drawing. For the evaluation of interference type II multiple points of the tool tip need to be tested which adds a new dimension of discretization to the model and the detailed tool profile must be available. It can be assumed that a good estimation of the interference situation can be performed by approximating the tools profile with a classical involute profile.

Apart from these limitations of the model, the implementation of the new approach in industrial workflows remains to be determined. Gear skiving tools are not necessarily used in the exact process which they were designed for because kinematic parameters are changed to optimize the resulting gearing quality or cutting conditions. Also the adapted parameters must not result in collision. In practice, tool manufacturers could calculate and provide viable tolerances for the kinematics parameters with the new approach. This elaborate procedure appears necessary as the two main parameters of quality improvement axis crossing angle and process eccentricity also mainly influence the interference situation.

In modern machine tool centers for gear machining, process kinematics are often automatically adapted to compensate for workpiece errors. The user transfers the gear measurement data while the machine automatically performs the necessary kinematics adaption. In this scenario, the user might not be aware of the actual kinematics changes and limits might be overlooked. In effect, the calculation of three dimensional meshing interference should be implemented into the machine software to be checked when calculating error compensations.

\section{Conclusion}

The three-dimensional modelling of meshing interference for crossed cylindrical as well as conical tool and helical ring gear configurations was successfully performed and applied for gear skiving. The implementation of the model was successfully validated by calculating an actual process with interference problems. The positive influence of reduc- a

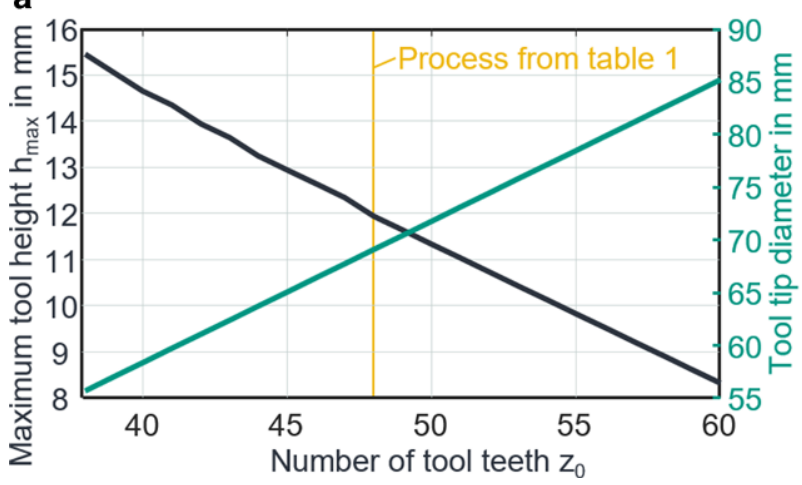

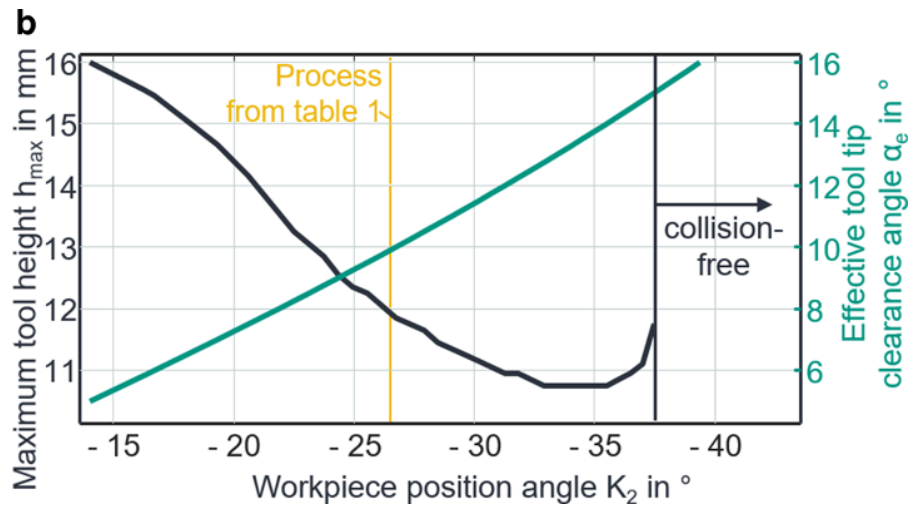

Fig. 9 a Maximum tool height versus tool teeth number $\mathbf{b}$ Maximum tool height versus tool eccentricity 


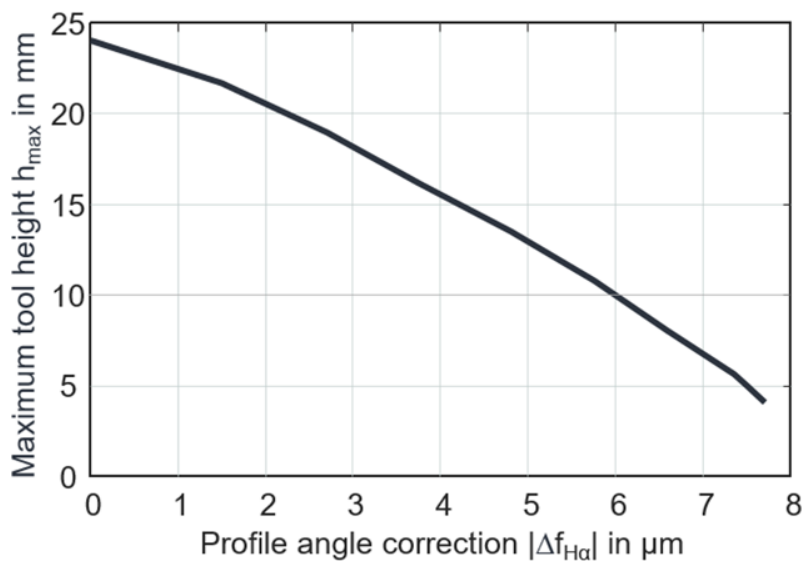

b

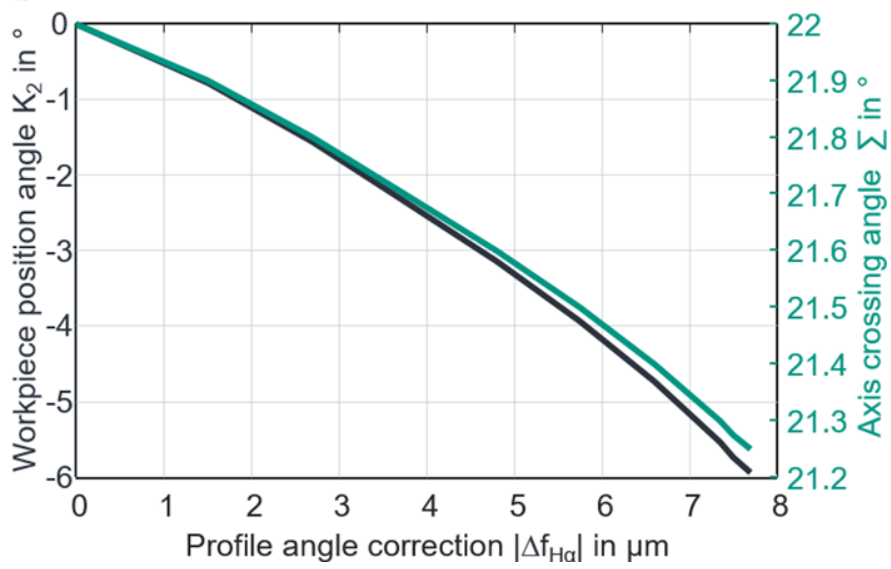

Fig. 10 a Maximum tool height over profile angle correction $\mathbf{b}$ Corresponding kinematics

ing the number of tool teeth known from involute spur gear setups was confirmed. In contrast, increasing the tool eccentricity first decreases maximum tool height and only large eccentricities render significant benefits. A second process example based on a conical tool design does not show interference in the standard process. But when the profile angle is to be corrected by only $2 \mu \mathrm{m}$ a tool height of only $20 \mathrm{~mm}$ will lead to collision. A higher profile error compensation could be possible when changing the tool clearance angle or the number of tool teeth, but with a given tool the error compensation is severely restricted. In addition, the manageable numerical limits of the model were discussed and implementation options of the model for tool and machine tool manufacturers are proposed. The implementation in machining centers and existing design methods has not yet been achieved, but seems beneficial to meet the current challenges of electro mobility ring gear manufacturing. In the future, the interference model should be analyzed in order to determine whether a fast analytical approach based on a detailed analysis of the generating gear with determinants of the gearing theory is possible. Furthermore, a comprehensive study on interference prevention workflows in the industrial environment is desirable.

Funding Open Access funding enabled and organized by Projekt DEAL.

Open Access This article is licensed under a Creative Commons Attribution 4.0 International License, which permits use, sharing, adaptation, distribution and reproduction in any medium or format, as long as you give appropriate credit to the original author(s) and the source, provide a link to the Creative Commons licence, and indicate if changes were made. The images or other third party material in this article are included in the article's Creative Commons licence, unless indicated otherwise in a credit line to the material. If material is not included in the article's Creative Commons licence and your intended use is not permitted by statutory regulation or exceeds the permitted use, you will need to obtain permission directly from the copyright holder. To view a copy of this licence, visit http://creativecommons.org/licenses/by/4. $0 \%$

\section{References}

1. Daniel B, Biermann T (2017) eAxle family in coaxial and offset arrangements. In: 6th International CTI Symposium Automotive Transmissions, HEV and EV Drives

2. Guo Z, Mao S, Huyan L, Duan D (2018) Research and improvement of the cutting performance of skiving tool. Mech Mach Theory $120: 302-313$

3. Bertsch D (2016) Optimierung der Werkzeug- und Prozessauslegung für das Wälzschälen von Innenverzahnungen. Dissertation, wbk Institute of Production Science, Karlsruhe

4. Albert R (2019) Wälzschälen: Optimale Verzahnungsqualität durch prozesssicheres Spannen und Einstellen der Werkzeuge. In: 3. Fachseminar Wälzschälen/Power-Skiving, IWU Chemnitz, April 3

5. Schulze V (2019) Untersuchung von Schneidstoffen und Prozessparametern für das Fertigungsverfahren Wälzschälen von hochfesten Innenverzahnungen - Schlussbericht zu IGF-Vorhaben Nr. 19076N. wbk Institute of Production Science, Karlsruhe

6. Guo Z, Mao S, Li X, Ren Z (2016) Research on the theoretical tooth profile errors of gears machined by skiving. Mech Mach Theory 97:1-11

7. Linke H, Börner J, Heß R (2016) Cylindrical gears. Calculation-Materials-Manufacturing, 2nd edn. Carl Hanser, Munich Vienna

8. Hühsam A (2006) Modellbildung und experimentelle Untersuchung des Wälzschälprozesses. Dissertation, wbk Institute of Production Science, Karlsruhe

9. Marinov S, Alipiev O, Uzunov T, Ren Z (2019) Interference of the profiles when meshing internal straight splines with gear shapers, machined by skiving. In: MATEC Web of Conferences-Power Transmissions 2019, vol 287

10. Bauer R (2018) Modellbasierte Auslegung von Mehrschnittstrategien beim Wälzschälen. Dissertation, Technical University Chemnitz 